\title{
Hierarchical approach to hydrological model calibration
}

\author{
Ayfer Ozdemir $^{1,2} \cdot$ Ugur Murat Leloglu $^{2} \cdot$ Karim C. Abbaspour $^{1}$
}

Received: 8 February 2016/Accepted: 7 March 2017/Published online: 19 April 2017

(C) Springer-Verlag Berlin Heidelberg 2017

\begin{abstract}
Hydrological models have been widely used for water resources management. Successful application of hydrological models depends on careful calibration and uncertainty analysis. Spatial unit of water balance calculations may differ widely in different models from grids to hydrological response units (HRU). The Soil and Water Assessment Tool (SWAT) software uses HRU as the spatial unit. SWAT simulates hydrological processes at sub-basin level by deriving HRUs by thresholding areas of soil type, land use, and slope combinations. This may ignore some important areas, which may have great impact on hydrological processes in the watershed. In this study, a hierarchical HRU approach was developed in order to increase model performance and reduce computational complexity simultaneously. For hierarchical optimization, HRUs are first divided into two-HRU types and are optimized with respect to some relevant influence parameters. Then, each HRU is further divided into two. Each child HRU inherits the optimum parameter values of the parent HRU as its initial value. This approach decreases the total calibration time while obtaining a better result. The performance of the hierarchical methodology is demonstrated on two basins, namely Sarisu-Eylikler and Namazgah Dam Lake Basins in Turkey. In Sarisu-Eylikler, we obtained good results by a combination of curve number (CN2), soil hydraulic conductivity, and slope for generating HRUs, while in Namazgah use of only CN2 gave better results.
\end{abstract}

Ayfer Ozdemir

ozdemir.ayfer@gmail.com

1 Eawag, Swiss Federal Institute of Aquatic Science and Technology, 8600 Dübendorf, Switzerland

2 Geodetic and Geographic Information Technologies Department, Middle East Technical University, 06800 Ankara, Turkey
Keywords SWAT - Calibration - Hydrological response unit · SUFI2 - Optimization

\section{Introduction}

Integrated planning and management of water resources at the basin scale is important for sustainable water management. Understanding of temporal and spatial distribution of recharge and contaminant loadings on river basin is needed for the proper management and protection of valuable water resources. Thus, the development and application of mathematical simulation models, which represent all the important hydrological processes at the suitable scale, is essential to provide a successful river basin management plan.

As distributed watershed models are increasingly used to produce alternative management strategies, careful calibration and uncertainty analysis of these models become more important (Duan et al. 1992; Beven and Binley 1992; Muleta et al. 2007; Vrugt et al. 2003; Arnold et al. 2012; Yang et al. 2008). Process-based hydrological models often include parameters that cannot be evaluated directly due to measurement restrictions and scale issues (Beven and Binley 1992; Kuczera 1997; Gupta et al. 1998; Beven 2000, 2006; Beven and Freer 2001; Harmel and Smith 2007; Holvoet et al. 2008; Zhang et al. 2008; Faramarzi et al. 2009; Moriasi et al. 2012a, b; Lenhart et al. 2002). In recent years, many calibration and uncertainty analysis methods were developed to improve reliability of model prediction and estimation of prediction uncertainty (Van Griensven and Meixner 2006; Abbaspour et al. 2007a, b, Marshall et al. 2004; Vrugt et al. 2003; Yang et al. 2008). However, calibration of the models is not an easy task because there are many uncertainties, namely input, model structure, parameter, and output uncertainties (Arnold et al. 2010). When the number of 
parameters used in the calibration is large, calibration can become labor-intensive and time-consuming (Balascio et al. 1998). Moreover, with increasing complexity of hydrological models, the complexity of calibration also increases (Gupta et al. 1998). Hence, methods that can calibrate models with large number of parameters in reasonable time are necessary.

In this study, one such method is described. For that purpose, the Soil and Water Assessment Tool (SWAT) (Arnold et al. 1998), which is a semi-physically based hydrological model used worldwide for evaluating water resources, is chosen. The smallest spatial unit of water balance calculation in SWAT is the hydrological response unit (HRU) in which the parameters are assumed to be constant. HRU generation in SWAT is based on user-defined thresholds to be applied to areas of soil, land use, and slope combinations at sub-basin level. The relation of these thresholds to the performance of the model is not well understood. If the number of HRUs is small, the HRUs are not uniform enough. If the number is high, then the number of parameters is large and optimization is difficult.

In this study, a hierarchical approach to HRU definition that increases model performance and reduces computational overhead simultaneously is presented. Although principal aim is reaching a better solution of the optimization problem in a shorter time, it helps in the understanding of the hydrological process as a by-product, because the best partition strategy and optimum number of levels give clues about underlying mechanism. Understanding and prediction of hydrological behavior, including the landscape characteristics that control hydrological response, the dominant processes associated with different landscape types, and the spatial relations of catchment processes are provided by HRU division methodology (Fenicia et al. 2016). The surface runoff is directly related to the CN (Jha et al. 2004). If $\mathrm{HRU}$ division method based on $\mathrm{CN} 2$ parameter gives better model performance than other HRU division methods, it suggests that surface runoff process is dominant in the basin. The performance of the hierarchical methodology (coarseto-fine) is demonstrated on two basins: Sarisu-Eylikler Basin and Namazgah Dam Basin in Turkey.

\section{Materials and methods}

\section{The SWAT hydrological model}

In SWAT, a watershed is divided into a number of subbasins based on the topography. Each sub-basin is further divided into HRUs, with unique land use, soil type, and slope combinations. Water balance is calculated at the HRU level and then aggregated to the whole sub-basin. Hydrological process simulation in SWAT occurs in two steps: (1) The model calculates upland flow and loadings of sediment, nutrients, bacteria, and pesticides from each HRU and then combines area-weighted HRU-level loadings to the sub-basin level; and (2) the model routes the upland loadings from each sub-basin through the channel/ stream network (Gassman et al. 2007).

\section{SUFI2 calibration program}

The SUFI2 algorithm (Abbaspour et al. 2004, 2007a, b) in the SWAT-CUP software (Abbaspour 2011) is used for calibration and uncertainty analysis in this study. The initial (large) uncertainties in the model parameters are gradually decreased until certain calibration criteria for prediction uncertainty are met in the SUFI2 procedure. The program uses Latin hypercube sampling with a global search algorithm that describes the behavior of objective function by analyzing the Jacobian and Hessian matrices (Abbaspour et al. 2007a, b).

\section{Hierarchical HRU approach}

The current HRU generation approach based on user-defined threshold values in SWAT has some disadvantages. If thresholds are too large, some important combinations may be ignored and included into other combinations resulting in non-uniform HRUs and eventually low performance, while, on the other hand, if thresholds are too small, a large number of HRUs may result, making parameterization and calibration a difficult task. In order to decrease the total calibration time and reach a solution closer to the global minimum of the objective function, hierarchical HRU approach is developed. For hierarchical optimization (coarse-to-fine), sub-basins are first divided into two-HRU types based on some important parameters, which have great impact in water cycle such as curve number, hydraulic conductivity, available water capacity and bulk density. Then, the model is optimized with respect to important parameters, which reflect relevant processes of the system, such as surface runoff, baseflow, lateral flow, sediment erosion, or nutrient cycling (Table 1). After the first level optimization, each HRU is further divided into two units. Each child HRU inherits the optimum parameters of the parent HRU as its initial values. As calibrated parameter values are used at each HRU-splitting step, this ensures a more efficient process and a better model fit. SUFI-2 is chosen for model calibration because it is shown to be more efficient than some other popular methods (Yang et al. 2008; Uniyal et al. 2015). Nash-Sutcliffe coefficient of efficiency (Nash and Sutcliffe 1970) is used to evaluate the goodness of fit of the calibration. At each run of the model and at the end of the calibration processes, the model accuracy is evaluated. If the result is not 
Table 1 Chosen SWAT calibration parameters and their ranges

\begin{tabular}{|c|c|c|c|c|}
\hline Parameters & MIN value & MAX value & Definition & Process/layer \\
\hline $\mathrm{CN} 2$ & -0.2 & 0.2 & Initial SCS runoff curve number & Surface runoff \\
\hline SURLAG & 0.05 & 24 & Surface runoff lag time & \\
\hline SOL_AWC & -0.2 & 0.1 & Available water capacity of the soil layer & Soil \\
\hline SOL_K & -0.8 & 0.8 & Saturated hydraulic conductivity $(\mathrm{mm} / \mathrm{h})$ & \\
\hline SOL_BD & -0.5 & 0.6 & Moist bulk density $\left(\mathrm{Mg} / \mathrm{m}^{3}\right.$ or $\left.\mathrm{g} / \mathrm{cm}^{3}\right)$ & \\
\hline GWQMN & 0 & 25 & $\begin{array}{l}\text { Threshold depth of water in the shallow aquifer required for } \\
\text { return flow to occur }\left(\mathrm{mm} \mathrm{H}_{2} \mathrm{O}\right)\end{array}$ & Baseflow \\
\hline GW_REVAP & -0.1 & 0 & Groundwater "revap" coefficient & \\
\hline REVAPMN & 0 & 500 & $\begin{array}{l}\text { Threshold depth of water in the shallow aquifer for } \\
\text { "revap" or percolation to the deep aquifer to occur }\left(\mathrm{mm} \mathrm{H}_{2} \mathrm{O}\right)\end{array}$ & \\
\hline ALPHA_BF & 0 & 1 & Baseflow alpha factor (days) & \\
\hline GW_DELAY & 30 & 450 & Groundwater delay time (days) & \\
\hline ESCO & 0.8 & 1 & Soil evaporation compensation factor & \\
\hline SFTMP & -20 & 20 & Snowfall temperature $\left({ }^{\circ} \mathrm{C}\right)$ & Snow \\
\hline SMTMP & -20 & 20 & Snowmelt base temperature $\left({ }^{\circ} \mathrm{C}\right)$ & \\
\hline SMFMX & 0 & 20 & Melt factor for snow on June $21\left(\mathrm{~mm} \mathrm{H}_{2} \mathrm{O} /{ }^{\circ} \mathrm{C}\right.$-day $)$ & \\
\hline SMFMN & 0 & 20 & Melt factor for snow on December $21\left(\mathrm{~mm} \mathrm{H}_{2} \mathrm{O} /{ }^{\circ} \mathrm{C}\right.$-day $)$ & \\
\hline TIMP & 0 & 1 & Snow pack temperature lag factor & \\
\hline
\end{tabular}

reasonable, HRU types are increased until acceptable results or the steady state is reached. If the result does not improve with increasing number of HRUs, HRU generation methodology is changed (Fig. 1). Sixteen parameters in Table 1 are used for calibration of HRU types in all experiments. In this paper, two methods are used: one based on a combination of important parameters for water cycle in the watershed and the other based on the most important parameter only. However, other methods can be adapted considering the characteristics of the basin under question. The performance of HRU division method shows which physical process is dominant in the basin since HRUs are generated according to some important parameter for water cycle in the basin.

Although the total number of subbasins have very little effect, threshold levels does not significantly affect the predicted levels of these environmental indicators. These threshold sub-watershed sizes can be used to optimize input data preparation requirements for SWAT analyses of other watersheds, especially those within a similar size range. The fact that different thresholds emerged for the different indicators also indicates the need for SWAT users to assess which indicators should have the highest priority in their analyses.

\section{Study area and model setup}

The methodology was applied on two different areas in Turkey, namely Sarisu-Eylikler Stream Basin, Konya, and Namazgah Dam Basin, Izmit. The calibration of the test areas we have used is specifically difficult because only single gauge at the main outlet of each is available. The technique that we have demonstrated is particularly useful in this kind of difficult settings. The first is located between $37.47^{\circ}$ and $38.15^{\circ} \mathrm{N}$ latitudes and $31.73^{\circ}-32.47^{\circ} \mathrm{E}$ longitudes in Konya Closed Basin, Turkey. The area of the basin is $1040 \mathrm{~km}^{2}$, and the average total annual flow of Sarisu-Eylikler Stream was 68 million $\mathrm{m}^{3}$ between 1992 and 2010 (Ozdemir and Leloglu (2014)). The digital elevation model (DEM), which was generated from 1:25,000-scale topographic maps, was used to delineate sub-basins. Based on the DEM and the stream network, a threshold drainage area of $115 \mathrm{~km}^{2}$ was chosen to discretize the basin into seven sub-basins. SWAT calculated the minimum, the maximum, and the mean values as well as the standard deviation of elevation as $1123,2337,1420$, and $195 \mathrm{~m}$, respectively. The soil and land use maps are essential for creating HRUs. The land use layer and the soil map were obtained from a Ministry of Forestry and Water Affairs project. There are fourteen land use/land cover classes in the study area. The most dominant types of land use in the basin are agricultural landclose grown, garrigue, and pasture. There are mostly reddishchestnut and limeless brown forest soil types in the basin. There is one outlet that shows sum of flows of all streams in the basin. Sarisu-Eylikler stream gauging station is used for comparing the results of the models to the observation data. The entire simulation period is from 1992 to 2010.

Namazgah Dam Basin, whose area is $100,64 \mathrm{~km}^{2}$, is located between $40.055^{\circ}$ and $41.004^{\circ} \mathrm{N}$ latitudes and $30.00^{\circ}-30.025^{\circ} \mathrm{E}$ longitudes in Kandira and Izmit District 


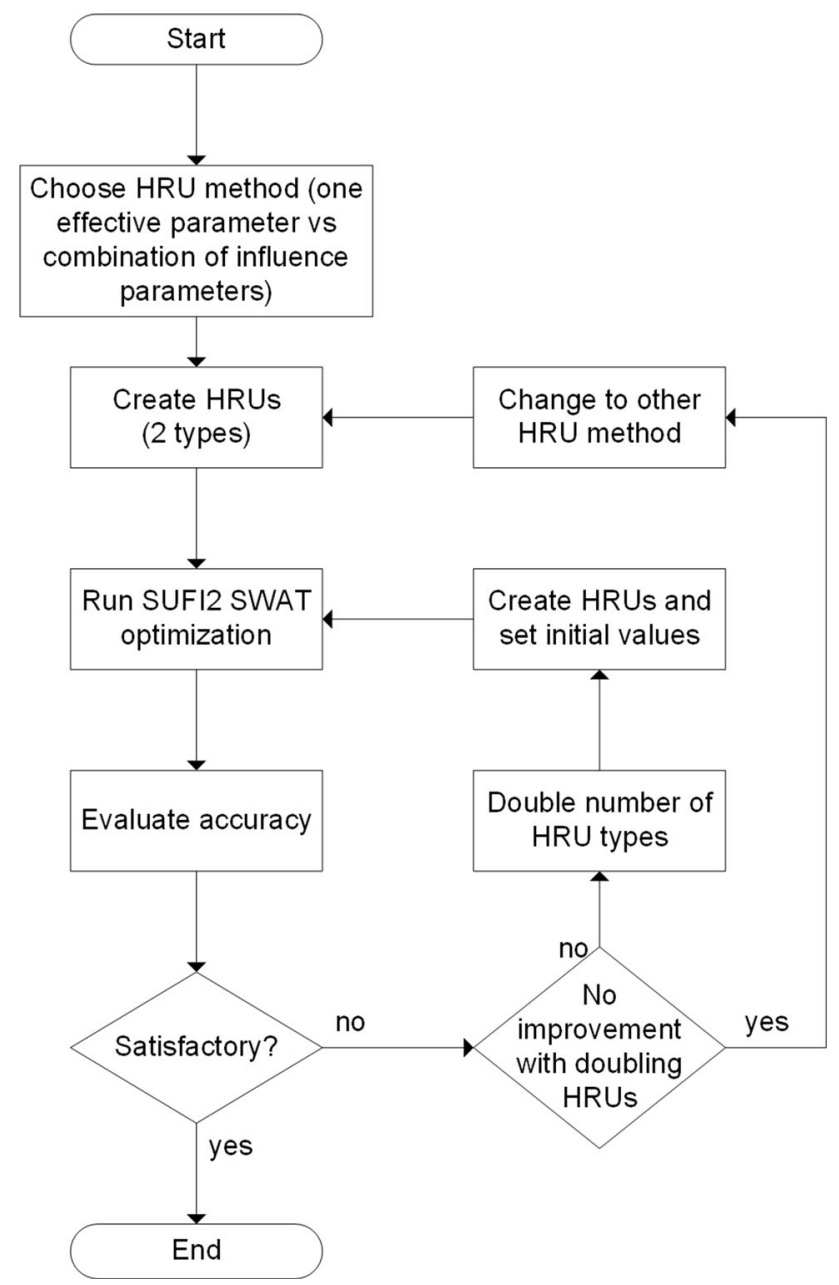

Fig. 1 The main algorithm

boundaries. The average total monthly flow of Namazgah Stream was $1.90 \mathrm{~m}^{3} / \mathrm{s}$ between 1991 and 2007. Namazgah Dam watershed was divided into five sub-basins based on the DEM that was produced from 1:25,000-scale topographic maps by using a threshold drainage area of $10 \mathrm{~km}^{2}$. The soil and land use maps of the study area were obtained from a Kocaeli Metropolitan Municipality project. There are mostly $N$ and $R$ group of soils, limeless brown forest and rendzina soils, in the area. There are eight land use/land cover classes in the study area. The most dominant types of land use are agricultural area and broad-leaved forest. There is one outlet which shows sum flows of all streams in the basin. Namazgah Stream gauging station in the basin was used for comparing the results of the models to the observation data. The entire simulation period is from 1991 to 2007.

Default curve number, default soil hydraulic conductivity and slope combinations are used for HRU generation in Sarısu-Eylikler Basin (Fig. 2). For Namazgah Dam Basin, $\mathrm{CN} 2$ curve number parameter is chosen for generating HRU types since it is thought that the parameter may have great influence for water dynamics (Fig. 3). A threshold on CN2 found from land use/soil tables in the SWAT manual is used to divide the sub-basins into two HRUs. This guaranties that the two HRUs are more or less uniform within themselves with respect to the CN2 parameter. Then, each HRU is further divided into two HRUs. For each method, threshold values of parameters depend on study area properties, which are topography, soil type, land use, etc.

\section{Results}

\section{Sarisu-Eylikler results}

The current HRU creation method implemented in SWAT is used as the baseline to be compared to the proposed method depending on the total HRU number in seven subbasins. Firstly, seven HRUs in total are obtained (one in each sub-basin) using dominant land use/land soil and slope combination approach. The uncalibrated model performances, $r^{2}=0.32$, NS $=0.43$, improve to $r^{2}=0.53$, $\mathrm{NS}=0.52$ after calibration. When the total HRU number is increased to 14 by using $25 / 25 / 50 \%$ threshold values for land use/soil/slope combination, the performance of the uncalibrated model, $r^{2}=0.34, \mathrm{NS}=-10$, improves to $r^{2}=0.35 \mathrm{NS}=0.32$ after the calibration. Finally, when 20/20/60\% threshold values for land use/soil/slope combination are used, the total number of HRUs is 21 . The performance of the uncalibrated model, $r^{2}=0.34$, $\mathrm{NS}=-2.69$, improves to $r^{2}=0.36$, NS $=0.32$ after the calibration.

Using the first method, each of the seven sub-basins is divided into two HRUs (two-HRU type). Thirteen HRUs are obtained instead of 14, because one of the sub-basin contains only one HRU type. The performance of the uncalibrated model, $r^{2}=0.32$, NS $=-0.16$, improves to $r^{2}=0.50, \mathrm{NS}=0.49$ after the calibration (Fig. 4a).

In the second step, each of the two HRUs above is further divided into two HRUs (four-HRU type) resulting in a total of 16 HRUs. The performance of the uncalibrated model, $r^{2}=0.41, \mathrm{NS}=0.11$, improves to $r^{2}=0.51$, $\mathrm{NS}=0.51$ after the calibration (Fig. 4b).

In the third step, the four-HRU type model is run with the calibrated parameters of the two-HRU type model and obtained initial results, $r^{2}=0.53$, NS $=0.31$, that improve to $r^{2}=0.59$, NS $=0.57$ (Fig. 4c) with the calibration.

In order to find the optimum HRU number, the HRUs in the four-HRU type model are further divided into two HRUs resulting in eight-HRU type model. The accuracy of the eight-HRU type model without including calibration processes is initially $r^{2}=0.21$, NS $=-0.21$, which is 
Fig. 2 HRU generation by combining $\mathrm{CN} 2$, soil hydraulic conductivit,y and slope classification

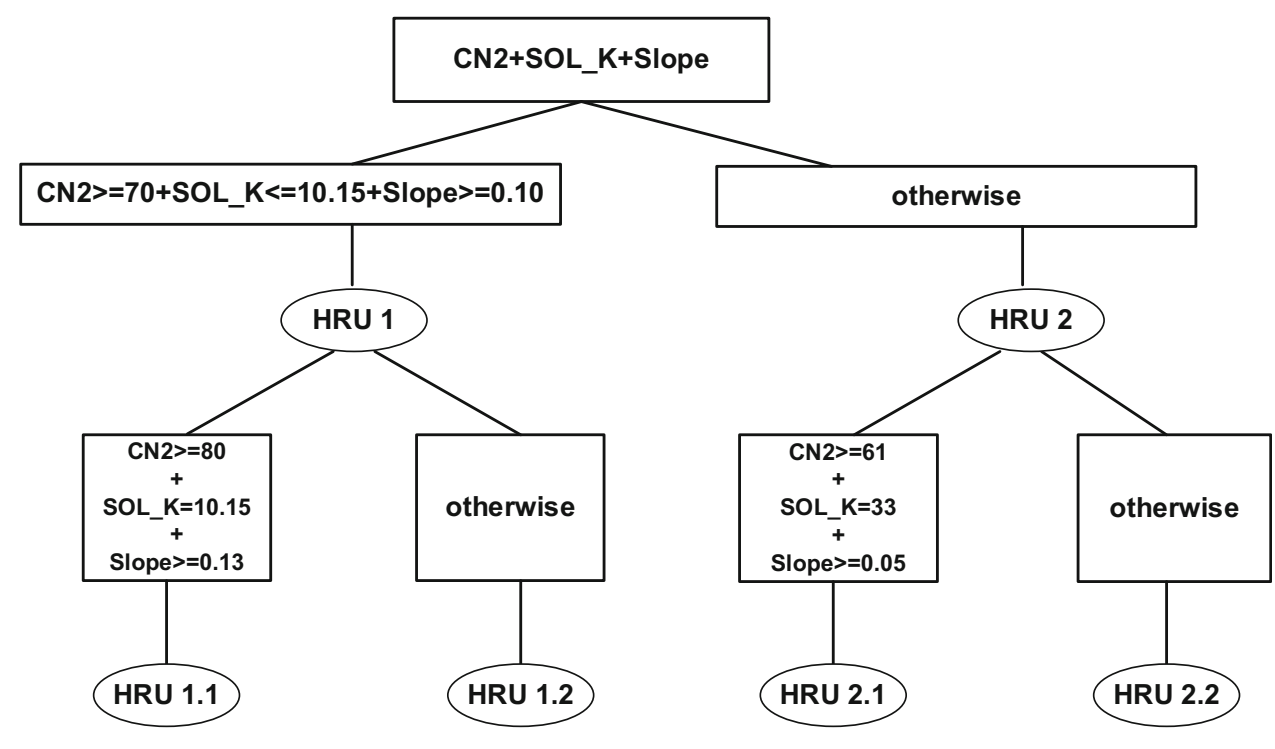

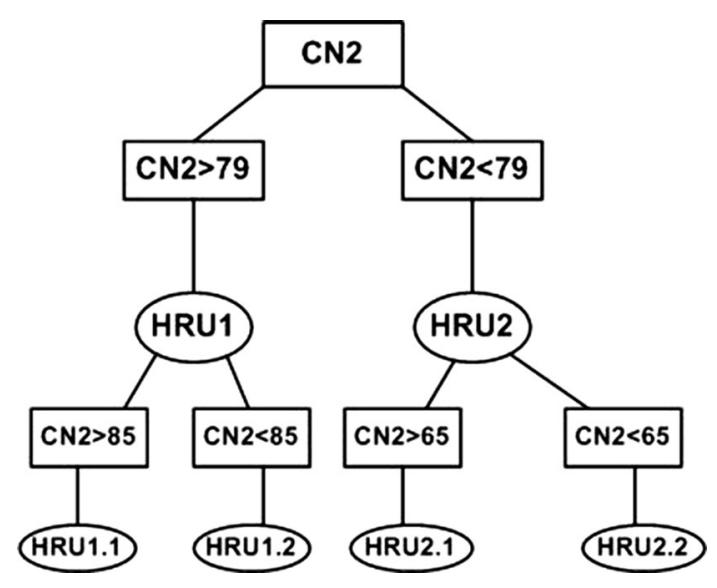

Fig. 3 HRU generation based on $\mathrm{CN} 2$

calibrated to produce $r^{2}=0.56$, NS $=0.51$ (Fig. 4d). Introducing calibrated parameters of the four-HRU model into the eight-HRU model, the initial run produces $r^{2}=0.24$, NS $=-0.10$, and calibrating it produces $r^{2}=0.53$, NS $=0.52$ (Fig. 4e), which do not improve the previous results. The results of Sarisu-Eylikler are summarized in Table 2 and Fig. 5.

\section{Namazgah Dam Basin results}

Again, the current HRU creation method implemented in SWAT is used as the baseline for comparison. Firstly, five HRUs in total are obtained (one in each sub-basin) using dominant land use/land soil and slope combination approach. The performance of the uncalibrated model of five HRUs, $r^{2}=0.3784, \mathrm{NS}=-1.37$, improves to $r^{2}=0.69, \mathrm{NS}=0.56$ after the calibration. When the total number of HRUs is increased to 12 by using 20/20/60\% threshold values, the performance of the uncalibrated model, $r^{2}=0.37$, NS $=-1.34$, improves to $r^{2}=0.70$, NS $=0.58$ after the calibration. Finally, when $10 / 10 / 80 \%$ threshold values are used, the total number of HRUs is 17 . The performance of the uncalibrated model, $r^{2}=0.39$, $\mathrm{NS}=-1.33$, improves to $r^{2}=0.68$, NS $=0.57$ after the calibration.

Using the second method for HRU generation, two HRUs are created in each of the five sub-basins, resulting in eight HRUs. The performance of the uncalibrated model, $r^{2}=0.37, \quad \mathrm{NS}=-1.47, \quad$ improves to $r^{2}=0.71$, NS $=0.71$ after the calibration. In the second step, a fourHRU model is produced with uncalibrated model results $r^{2}=0.43, \mathrm{NS}=-0.79$, which improves to $r^{2}=73$, $\mathrm{NS}=72$ after the calibration.

In the third step, the four-HRU type model is used with the calibrated parameters of the two-HRU type model with $r^{2}=0.59, \mathrm{NS}=0.10$, which improves to $r^{2}=0.74$, $\mathrm{NS}=0.73$ after the calibration.

In order to find optimum HRU numbers, eight-HRU type model is created. The model accuracies of eight-HRU types are initially $r^{2}=46$, NS $=-0.14$, which improve to $r^{2}=73, \mathrm{NS}=72$ after the calibration. The results of Namazgah Dam are summarized in Table 3.

\section{Discussion}

As the current HRU method in SWAT is based on userdefined thresholds of soil land use and slope classification combinations, it may result in ignoring some important combinations, which may have great impact on the 
Fig. 4 Sarisu-Eylikler results. a Model calibration results of two HRUs, which are generated by $\mathrm{CN} 2+$ SOL_K + slope, b model calibration results of four HRUs, c model calibration results of four HRUs, two-HRU types calibrated model parameters used as initial values for four HRUs, $\mathbf{d}$ model calibration result of eight HRUs, e model calibration model results of eight HRUs, fourHRU types calibrated model parameters used as initial values for 8 HRUs
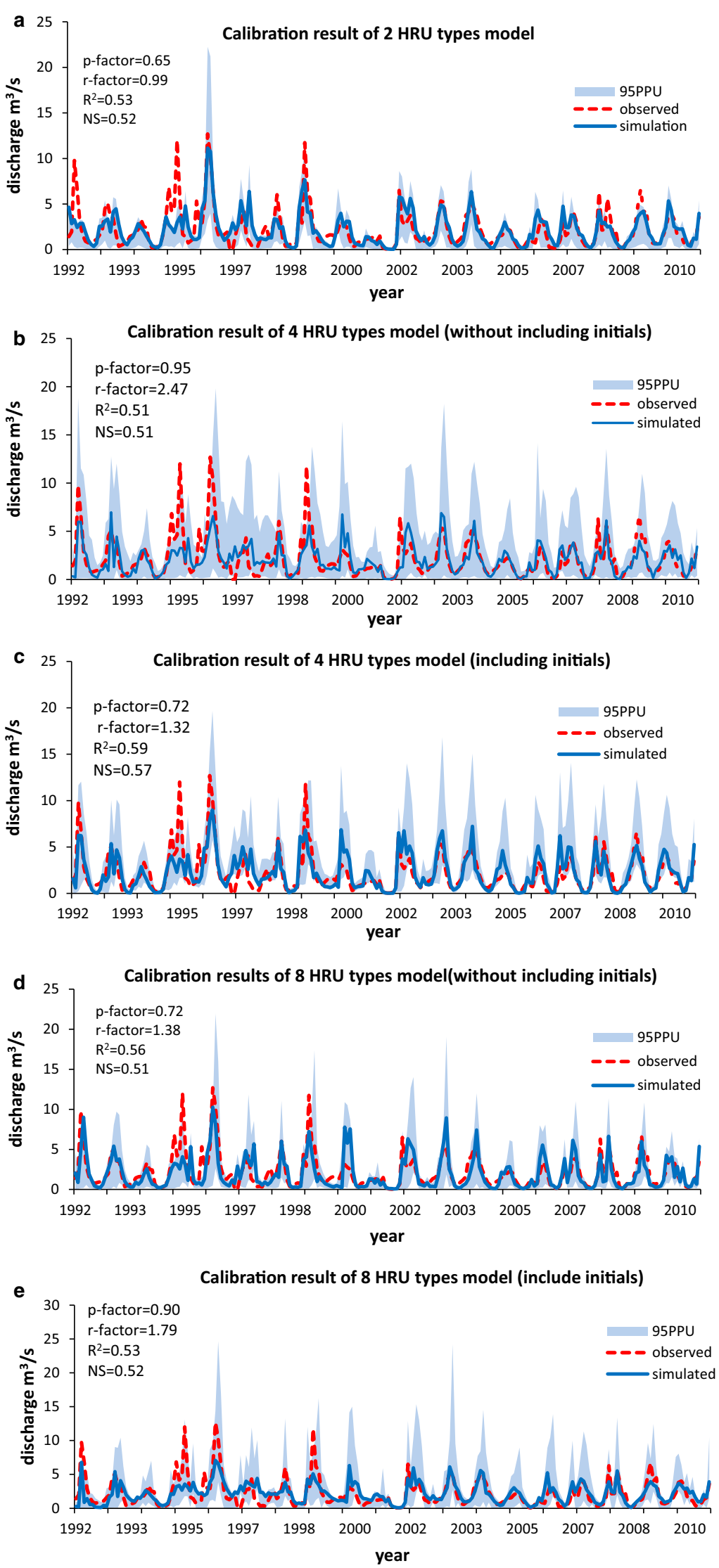
Table 2 Summary of results for Sarisu-Eylikler Basin

\begin{tabular}{lccc}
\hline Method & Total \# of & $\begin{array}{c}\text { Initial model } \\
R^{2}, \text { NS }\end{array}$ & $\begin{array}{c}\text { After calibration } \\
R^{2}, \text { NS }\end{array}$ \\
\hline ArcSWAT (dominant land use/slope/soil) & 7 & $0.33,-10$ & $0.36,0.24$ \\
ArcSWAT (25/25/50\% threshold values for land use/soil/slope) & 14 & $0.34,-10$ & $0.35,0.32$ \\
ArcSWAT (20/20/60\% threshold values for land use/soil/slope) & 21 & $0.34,-2.69$ & $0.36,0.32$ \\
CN2KS (CN2, soil hydraulic conductivity and slope combination), two-HRU types & 13 & $0.32,-0.16$ & $0.50,0.49$ \\
CN2KS, four-HRU types & 16 & $0.41,0.11$ & $0.51,0.51$ \\
CN2KS, four-HRU types, initials from two HRUs & 16 & $0.53,0.31$ & $0.59,0.57$ \\
CN2KS, eight-HRU types & 18 & $0.21,-0.21$ & $0.56,0.51$ \\
CN2KS, eight-HRU types, initials from four HRUs & 18 & $0.24,-0.10$ & $0.53,0.52$ \\
\hline
\end{tabular}

Fig. 5 Summary of HRU types results for Sarisu-Eylikler Basin

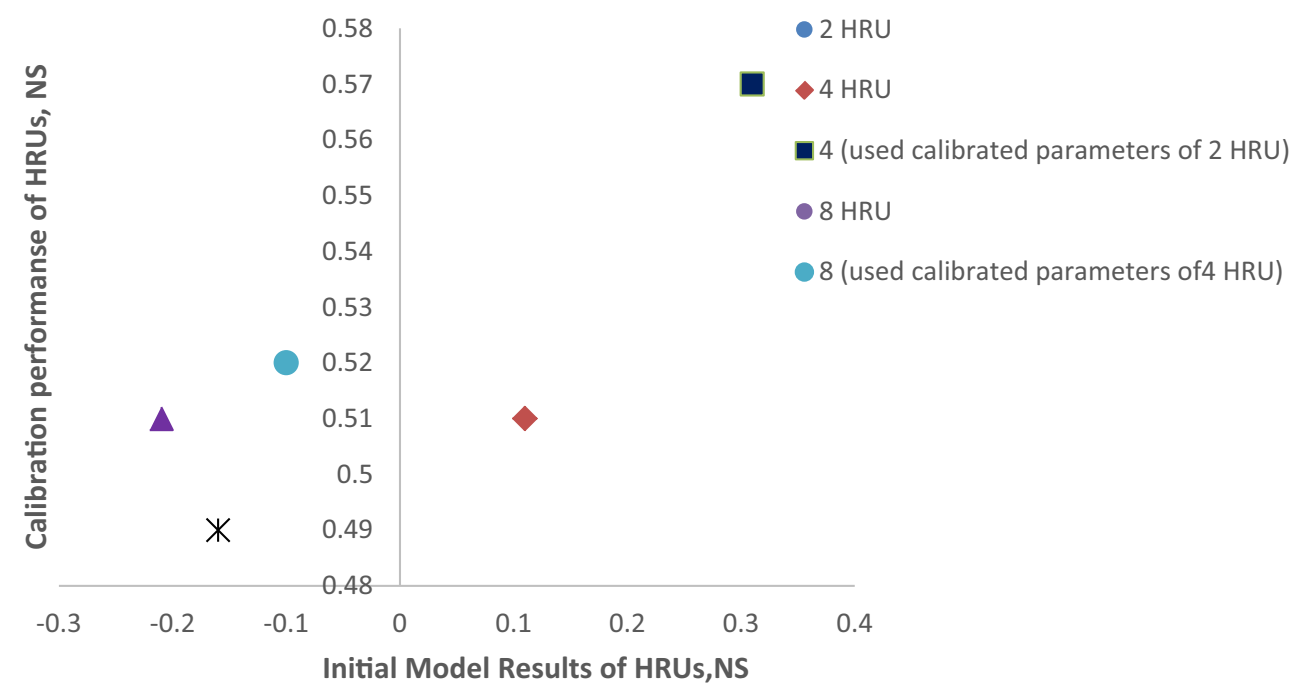

Table 3 Summary of results for Namazgah Dam Basin

\begin{tabular}{lccc}
\hline Method & Total \# of HRUs & Initial Model $R^{2}$, NS & After calibration $R^{2}$, NS \\
\hline ArcSWAT (dominant land use/slope/soil) & 5 & $0.38,-1.37$ & $0.69,0.56$ \\
ArcSWAT (20/20/60\% threshold values for land use/soil/slope) & 12 & $0.38,-1.34$ & $0.70,0.58$ \\
ArcSWAT (10/10/80\% threshold values for land use/soil/slope) & 17 & $0.39,-1.33$ & $0.68,0.57$ \\
CN2, two-HRU types & 13 & $0.37,-1.47$ & $0.71,0.71$ \\
CN2, four-HRU types & 13 & $0.43,-0.79$ & $0.73,0.72$ \\
CN2, four-HRU types, initials from two HRUs & 13 & $0.59,0.10$ & $0.74,0.73$ \\
CN2, eight-HRU types & 14 & $0.46,-0.14$ & $0.73,0.72$ \\
\hline
\end{tabular}

hydrological process in a watershed. As a result, the model performance declines and calibration takes a long time. Using small and relatively uniform HRUs reduces the error caused by lumping effects (Geza and McCray 2008), but makes calibration more difficult and increases required computation time.

In this work, a hierarchical approach is adopted, similar to many other optimization problems, in order to increase model performance and reduce computational complexity simultaneously. For hierarchical optimization, each sub-basin is divided into two HRUs and optimized with respect to some important hydrological process parameters. Then, each HRU is further divided into two. Each child HRU inherits the optimum parameters of the parent HRU as its initial values. The HRUs are divided until the maximum HRU number best suited to describe the process in the basin is found. Thus, the total calibration time is expected to decrease and the performance of the model is expected to increase. 
Hierarchical approach (coarse-to-fine) to hydrological model is applied on two different test areas in Turkey with different hydrological, topographic, and hydrogeologic conditions. Although the maximum elevation in the SarisuEylikler Basin is $2400 \mathrm{~m}$, in Namazgah Dam Basin the maximum elevation is $320 \mathrm{~m}$. While choosing outlet for comparing model results with observed results, the gauging station is selected because it shows all flows in the basin. For both basins, there is one station which represents all flows in the basin. Moreover, the station was chosen by paying attention not to be in front of an artificial structure. There are 17 different soil types in Sarısu-Eylikler Basin. The most dominant soil types in the basin are reddishchestnut and limeless brown soils. There are mostly agricultural, garrigue, and pasture areas in the basin, so the area is heterogeneous. The characteristics of the area affect the choice of the HRU generation method. When SOL_K and CN2 parameters are chosen independently for the division of HRU types, the model performance is not so good. Since these parameters cannot represent all hydrological processes in the watershed area individually, the combination of these parameters, which are CN2, SOL_K, and slope classification, is preferred. Namazgah Dam Basin has more homogeneous properties than Sarısu-Eylikler Basin. The most dominant soil type is limeless brown forest soil, which covers approximately $60 \%$ of the watershed area. There are two dominant land covers in the basin that are agricultural land and broad-leaved forest with areas of 67.3 and $24.9 \%$, respectively. There are many karstic areas in Namazgah Dam Basin where groundwater is recharged from surface water (Altuntas et al. 2015). Besides the topography difference, the area of the Namazgah Dam Basin is smaller than that of Sarısu-Eylikler Basin. Moreover, Namazgah Dam Basin shows homogenous characteristics. So one important parameter for generating HRU types, CN2, can represent all hydrological processes in the watershed area.

In the current HRU method, relatively same model results and calibration performance are obtained for a range of HRU numbers (Tables 2, 3). From seven to 21 total HRU numbers, initial model results and calibration performance are almost same in the Sarisu-Eylikler Basin. Similarly, from five to 17 HRUs results do not change significantly in the Namazgah Dam Basin, as expected.

In the hierarchical approach, when four-HRU types are separated further into two-HRU types in Sarisu-Eylikler Basin, total number of HRUs in the model does not increase much, and further division causes many gaps in the model. In other words, when eight-HRU types are generated, some combinations for producing HRU types do not exist in most of the sub-basins. Although the model performance gets worse, model calibration performance gets better. These results show that the optimum division of
HRU types should be four HRUs for Sarisu-Eylikler Basin. With increasing complexity of the model, the uncertainties increase. Thus, HRU types more than four cause more uncertainties in the model (Table 2; Fig. 5).

When CN2 division approach is tested in Namazgah Dam Basin, the model gives us better $r^{2}$ values from two HRUs to four HRUs. However, calibration results of two HRUs and four HRUs are approximately the same. If calibrated parameter values of two HRUs are used as initials for four HRUs, the model gets better and computational time for calibration declines. If four HRUs are divided into two children, model performance and calibration effort for eight HRUs are similar to four HRUs since the total number of HRUs in the basin during generation of eightHRU types does not increase much. In other words, although the total HRU number of four-HRU type is 13 , the total HRU number of eight-HRU types is 14. Thus, HRU division is stopped, because optimum HRU type division is four (Table 3).

Although principal aim is reaching a better solution of the optimization problem in a shorter time, it helps in the understanding of the hydrological process as a by-product, because the best partition strategy and optimum number of levels give clues about underlying mechanism. In both basins, the hierarchical HRU method gives better model and calibration performance results. When much more detailed hydrological models are needed, especially for applying water management policy in the watershed, the hierarchical approach for HRU division can be best approach for model accuracy. It should be considered that before applying the methodology, the basin should be understood correctly with respect to its physical properties.

\section{Conclusion}

The hierarchical HRU approach to hydrological model calibration is developed in order to increase model performance and reduce computational complexity simultaneously. The first method for the approach is combination of CN2, soil hydraulic conductivity, and slope classification, while the second method for producing HRU types is based on $\mathrm{CN} 2$ division. The performance of the hierarchical methodology is shown on two basins: Sarisu-Eylikler Basin and Namazgah Dam Lake in Turkey. According to these results, the following conclusions can be drawn:

1. HRU division method should be chosen depending on basin hydrological characteristics. First approach for generation of HRU types gives us better results in Sarısu-Eylikler Basin, while the second method performs better for the Namazgah Dam Basin. Although 
surface runoff in Namazgah Dam Basin is mainly affected by land use variations, hydrological processes in Sarisu-Eylikler Basin are mainly affected by soil type, land use, and topography. Hence, the best working strategy gives clues about the character of the basin.

2. According to first HRU division approach shown in Fig. 2, the model performance in the Basin improved from two- to four-HRU types. Although, the model performance of the eight-HRU types does not improve the results, the computational time for calibration of four-HRU types is reduced.

3. By using the second approach of hierarchical optimization shown in Fig. 1, better results on Namazgah Dam Basin are reached. The model performance increased and the computational complexity decreased from the two-HRU type to the four-HRU type,

4. The proposed HRU generation method gives us better results than the current HRU generation approach in SWAT.

5. Hierarchical approach to HRU generation is suitable for heterogeneous and large-scale basins.

Developed methodology for generation of HRU division in hydrological models can improve model accuracy and decrease computational complexity for calibration. Moreover, the results show that further model complexity does not give more accurate model results after second level. While using better available data, more accurate model prediction and smaller uncertainties can be reached by using the methodology. In the future, the proposed methodology can be applied to semi-distributed models other than SWAT or can be applied to SWAT but with optimization methods other than SUFI2. Besides, the method needs to be tested on various basins to establish guidelines for HRU division strategies.

Acknowledgements The authors would like to thank TUBITAK (2211 C and 2214 A programs) for providing support for this project. We also would like to thank Ali ERTURK for helpful advices.

\section{References}

Abbaspour KC (2011) User manual for SWAT-CUP, SWAT calibration and uncertainty analysis programs. Eawag: Swiss Federal Institute of Aquatic Science and Technology, Duebendorf, Switzerland. http://swat.tamu.edu/software/swat-cup/

Abbaspour K, Johnson C, Van Genuchten MT (2004) Estimating uncertain flow and transport parameters using a sequential uncertainty fitting procedure. Vadoze Zone J 3:1340-1352. doi:10.2136/vzj2004.1340

Abbaspour KC, Vejdani M, Haghighat S (2007a) SWATCUP calibration and uncertainty programs for SWAT. In: Oxley L, Kulasiri D (eds) Proceedings of the international congress on modelling and simulation (MODSIM'07). Modelling and
Simulation Society of Australia and New Zealand, Melbourne, Australia, pp 1603-1609

Abbaspour KC, Yang J, Maximov I, Siber R, Bogner K, Mieleitner J, Srinivasan R (2007b) Modelling hydrology and water quality in the pre-alpine/alpine Thur watershed using SWAT. J Hydrol 333:413-430. doi:10.1016/j.jhydrol.2006.09.014

Altuntaş A, Özdemir A, Koç A, Turan G (2015) Namazgah Baraj Gölü Havzasi'nda Yeraltisuyu ve Yüzey Suyu İlişkisinin Koruma Alanlarinin Doğal İzotoplarla Belirlenmesi. In: 4 National isotope techniques at hydrology symposium, Istanbul, Turkey

Arnold JG, Srinivasan R, Muttiah RS, Williams JR (1998) Large-area hydrologic modeling and assessment: part I. Model development. J Am Water Resour Assoc 34:73-89

Arnold JG, Allen PM, Volk M, Williams JR, Bosch DD (2010) Assessment of different representations of spatial variability on SWAT model performance. Am Soc Agric Biol Eng 53:1433-1443

Arnold JG, Moriasi DN, Gassman PW, Abbaspour KC, White MJ, Srinivasan R, Jha MK (2012) SWAT: model use, calibration and validation. Am Soc Agric Biol Eng 55(4):1491-1508

Balascio CC, Palmeri DJ, Gao H (1998) Use of a genetic algorithm and multi-objective programming for calibration of a hydrologic model. Trans ASAE 41:615-619

Beven KJ (2000) Rainfall-runoff modeling: the primer. Wiley, New York

Beven KJ (2006) A manifesto for the enquiringly thesis. J Hydrol 320:18-36

Beven K, Binley A (1992) The future of distributed models-model calibration and uncertainty prediction. Hydrol Process 6:279-298

Beven KJ, Freer J (2001) Equifinality, data assimilation, and uncertainty estimation in mechanistic modeling of complex environmental systems. J Hydrol 249:11-29

Duan Q, Sorooshian S, Gupta V (1992) Effective and efficient global optimization for conceptual rainfall-runoff models. Water Resour Res 28(4):1015-1031

Faramarzi MK, Abbaspour KC, Schulin R, Yang H (2009) Modeling blue and green water availability in Iran. Hydrol Process 23(3):486-501

Fenicia F, Kavetski D, Savenije HHG, Pfister L (2016) From spatially variable streamflow to distributed hydrological models: analysis of key modeling decisions. Water Resour Res 52:1-36

Gassman PW, Reyes MR, Green CH, Arnold JG (2007) The soil and water assessment tool: historical development, applications, and future research directions. Am Soc Agric Biol Eng 50(4):1211-1250

Geza M, McCray JE (2008) Effects of soil data resolution on SWAT model stream flow and water quality predictions. J environ manage 88(3):393-406

Gupta HV, Sorooshian S, Yapo PO (1998) Toward improved calibration of hydrologic models: Multiple and noncommensurable measures of information. Water Resour Res 34(4):751-763

Harmel RD, Smith PK (2007) Consideration of measurement uncertainty in the evaluation of goodness of fit in hydrologic and water quality modelling. J Hydrol 337:326-336

Holvoet K, Griensven AV, Gevart V, Seuntjens P, Vanrolleghem PA (2008) Modifications to the SWAT code for modelling direct pesticide losses. Environ Model Softw 23:72-81

Jha M, Gassman PW, Secchi S, Gu R, Arnold JG (2004) Effect of watershed subdivision on swat flow, sediment, and nutrient predictions. J Am Water Resour Assoc 40(3):811-825

Kuczera G (1997) Efficient subspace probabilistic parameter optimization for catchment models. Water Resour Res 33:177-185

Lenhart T, Eckhardt K, Fohrer N, Frede HG (2002) Comparison of two different approaches of sensitiviy analysis. Phys Chem Earth 27:645-654 
Marshall L, Nott D, Sharma A (2004) A comparative study of Markov chain Monte Carlo methods for conceptual rainfall-runoff modeling. Water Resour Res 40:2501. doi:10.1029/ 2003WR002378

Moriasi DN, Arnold JG, Liew MW, Bingner RL, Harmel RD, Veith TL (2012a) Model evaluation guidelines for systematic quantificaiton of accuracy in watershed simulations. Am Soc Agric Biol Eng 50:885-900

Moriasi DN, Wilson BN, Mankin KR, Arnold JG, Gowda PH (2012b) Hydrologic and water quality models: use, calibration, and validation. Am Soc Agric Biol Eng 55:1241-1247

Muleta MK, Nicklow JW, Bekele EG (2007) Sensitivity of a distributed watershed simulation model to spatial scale. J Hydrol Eng 12(2):163-172

Nash JE, Sutcliffe JV (1970) River flow forecasting through conceptual models part I-A discussion of principles. J hydrol 10(3):282-290

Ozdemir A, Leloglu UM (2014) Climate change impact assessment on river basin: Sarisu-Eylikler River, Turkey. In: 2nd
International sustainable watershed management conference, SuWaMa 2014. Sarıgerme, Turkey, pp 103-112

Uniyal B, Jha MK, Verma AK (2015) Parameter identification and uncertainty analysis for simulating streamflow in a river basin of Eastern India. Hydrol Process 29:3744-3766. doi:10.1002/hyp.10446

Van Griensven A, Meixner T (2006) Methods to quantify and identify the sources of uncertainty for river basin water quality models. Water Sci Technol 53:51-59

Vrugt JA, Gupta HV, Bouten W, Sorooshian S (2003) A shuffled complex evolution metropolis algorithm for optimization and uncertainty assessment of hydrologic model parameters. Water Resour Res 39(8):1201. doi:10.1029/2002WR001642

Yang J, Reicher P, Abbaspour KC, Xia J, Yang H (2008) Comparing uncertainity analysis techniques for a SWAT application to the Chaohe Basin in China. J Hydrol 358:1-23

Zhang X, Srinivasan R, Zhao K, Liew MV (2008) Evaluation of global optimization algorithms for parameter calibration of a computationally intensive hydrologic model. Hydrol Process 23:430-441 